\title{
A COMPARATIVE ANALYSIS OF LINGUISTIC ROUTINES IN TWO LANGUAGES: ENGLISH AND EWE
}

\author{
Felix AMEKA*
}

It is very widely acknowledged that linguistic routines are not only embodiments of the sociocultural values of speech communities that use them, but their knowledge and appropriate use also form an essential part of a speaker's communicative/pragmatic competence. Despite this, many studies concentrate more on describing the use of routines rather than explaining the socio-cultural aspects of their meaning and the way they affect their use. It is the contention of this paper that there is the need to go beyond descriptions to explanations and explications of the use and meaning of routines that are culturally and socially revealing. This view is illustrated by a comparative analysis of functionally equivalent formulaic expressions in English and Ewe. The similarities are noted and the differences explained in terms of the socio-cultural traditions associated with the respective languages. It is argued that insights gained from such studies are valuable for crosscultural understanding and communication as well as for second language pedagogy.

\section{Introduction}

There is increasing evidence in a number of interesting studies (for example, the papers in Coulmas (1981a)), which indicates that "linguistic routine (...) may (...) conceal the many intricacies of man's verbal behaviour and its study is sure to be of value both in practice and in theory" (Drazdauskiene (1981: 55)). Much of the work done though does not seem to have much to offer from a theoretical or even a wider practical point of view (cf. Haggo and Kuiper (1983)). Thus, although it is widely acknowledged that linguistic routines are culture-specific phenomena and their meanings cannot be interpreted apart from the socio-cultural context in which they are used, and furthermore that their use constitutes one problem area in cross-cultural and inter-ethnic communication, few have attempted to make explicit the meaning and cultural

* I would like to thank Eben Banful, Edith Bavin, Cathy Moran, Tim Shopen and Sakurako Todoriki for their helpful comments and the stimulating discussions I had with them on aspects of the paper. I owe a great debt to David Wilkins for his valuable comments, advice and suggestions on an earlier version of the paper. I cannot adequately express my indebtedness and profound gratitude to Anna Wierzbicka for her inspiring and encouraging remarks, guidance and many valuable suggestions on earlier fragments of the paper. However, the shortcomings and inadequacies that remain are my responsibility.

Author's address: F. Ameka, Faculty of Arts, Dept. of Linguistics, Australian National University, P.O.B. 4, Canberra, A.C.T. 2601, Australia. 
content of these routines in individual languages. Fewer still have essayed the task of comparing routines across cultures in a culture independent manner.

The purpose of this paper is to present an analysis of the meanings ${ }^{1}$ of functionally equivalent linguistic routines in two languages: English and Ewe ${ }^{2}$, and compare them in a culturally revealing manner. The aim is to bring out the similarities and differences and explain the latter in terms of the socio-cultural milieu in which the routines are used.

The plan of the paper is as follows: In section 2, some preliminary comments are made on linguistic routines and the method of analysis explained. This is followed in section 3 by a discussion of the meanings of selected expressions used in English and Ewe to give felicitations to people when good things happen to them. Section 4 examines some of the routines in both languages addressed to people who experience something bad. Section 5 concentrates on one conversational routine in Ewe which reflects an interesting social and cultural norm in Ewe society. Explicit semantic formulae are proposed to account for the meanings of each of the routines discussed.

\section{Linguistic routines: Some observations}

Communication in daily social intercourse in speech communities is largely manifested through the enactment of routines - be they verbal or non-verbal.

1 In this paper, 'meaning' is viewed in a very broad sense. It refers to any information that is associated with a linguistic routine and is needed for its interpretation - and which is coded systematically and conventionally expressed by it. Thus all the shared beliefs, attitudes and values of the speech community that uses the routines (and of the participants in a speech event) as well as the cognitive content, the social, cultural, affective and situational factors that have bearing on their use are all relevant. It is my conviction that all these aspects of routines can be explicated and represented in semantic formulae. Granting that such semantic representations are adequately formulated, it should be possible to predict various things about the usage of routines such as politeness and various conversational implicatures.

2 Ewe is a major dialect of the dialect-cluster which is preferably referred to now as Gbe (Capo (1983)) - a language of the Tano-Congo (or Kwa) branch of the Congo-Kordofanian family. Ewe is spoken in the south-eastern corner of Ghana (southern parts of the Volta Region of Ghana, to be precise) where it is in contact with English and across into the southern parts of Togo as far as and just across the Togo-Benin border where it is in contact with French. Ewe is also one of the two national languages of Togo.

Traditional Ewe orthography is used throughout the paper. In this system, ' $f$ ' ' $v$ ' and ' $d$ ' represent $[\Phi][\beta]$ and $[\underline{d}]$ respectively in IPA. (All other letters have their IPA value.) Although tones are sparingly marked traditionally, all high tones as well as the low tones that are conventionally marked are indicated with ' and ' respectively. "represents a rising tone while " represents nasalisation. The following abbreviations are used in interlinear translations.

$$
\begin{aligned}
& \mathrm{FOC}=\text { Focus } \quad \mathrm{PRO}=\text { Pronoun } \mathrm{HAB}=\text { Habitual } \mathrm{SG}=\text { Singular } \mathrm{L}=\text { First person } \\
& \text { NEG }=\text { Negative POSS }=\text { Possessive PL }=\text { Plural } Q=\text { Quest. Part. } 2=\text { Second person } \\
& \text { PRT = Particle } \quad 3=\text { Third person }
\end{aligned}
$$


The attention and interest of linguists have been drawn to prepatterned and prefabricated utterances or sequence of utterances that are used recurrently in more or less standardised communication situations in various communities. We follow Hymes (1968: 126) in referring to such expressions as linguistic routines $^{3}$ (cf. Saville-Troike (1982: 44-46)).

Linguistic routines used to be considered as "part of the dust of social activity, empty and trivial" conventions (Goffman (1971: 90)) used in everyday interaction for phatic communication. Now, the widespread view is that routines embody a lot of social, situational and cultural meanings. Few aspects of language furnish better clues to the cultural ecology and preoccupations of a speech community than linguistic routines (see Matisoff (1979), Tannen and Öztek (1981), Verschueren (1981) and Wierzbicka (1986a)). Furthermore, the use of some of these expressions involves politeness. Laver (1981: 290), for example, contends that: "routine behaviour is polite behaviour. The linguistic behaviour of conversational routines involving greetings and partings as well as pleas, thanks, excuses, apologies and small-talk is part of the linguistic repertoire of politeness"' (see also Ferguson (1976: 138), Brend (1978: 253), Lakoff (1973), Brown and Levinson (1978)).

These aspects of routines - the socio-cultural content of their meaning and politeness - which are culture-specific phenomena make the character and incidence of linguistic routines in various languages highly idiosyncratic to particular cultures (as reflected in particular (groups of) languages). Consequently their appropriate use in second language situations creates many difficulties (cf. Coulmas (1979), Ameka (1985), Akere (1978), Borkin and Reinhart (1978) among others). A practical value then of studying these should be the promotion of cross-cultural understanding and easing of problems in second language acquisition of these forms.

In addition, following from their culture-specific nature, one needs to enter the psycho-socio-cultural world of the particular speech community in order to understand, interpret and clucidate the knowledge that these expressions encapsulate. This, for some people, is perhaps the most important property of linguistic routines (cp. Saville-Troike (1982: 147)). Several studies of formulae in many languages bear testimony to this (e.g. Coulmas (1979, 1981b), Matisoff (1979), Verschueren (1981) inter alia). What is less easy to find are rigorous and explicit analyses of the very crucial cognitive, social and cultural components of the meanings of routines which are not couched in obscure and

3 Recent interest in the phenomenon of linguistic routines has led to a proliferation of terms. Unfortunately many writers do not make clear what the conceptual similarities and differences are between these terms although some of them are used interchangeably. Some of the terms likely to be encountered in the literature are: formulae; formulaic expressions; deference formulae; politeness formulae; routines; politeness routines; discourse routines; routine formulae; prepatterned discourse units, and stereotypes and gambits. The first two of these are used in this paper as synonyms of linguistic routines. 
ethnocentric language. No criticism of many available accounts of routines could be more apt than the challenging words of Matisoff (1979: 83): "How well have we isolated the individual psychosemantic components of such familiar speech acts as thanks, blessings, curses, oaths and the rest? How well have we translated the elusive inner language of our mental processes into the pseudo-precise language of expository prose?" (see Haggo and Kuiper (1983) for similar comments). The usefulness of most of the studies for cross-linguistic or cross-cultural comparative studies is as a result severely impaired.

This short-coming may be traced to the difficulty in incorporating sociocultural meanings within semantic frameworks. A number of proposals have been recently advanced for doing this, some with specific reference to representing the meaning of formulae in presumably a scientific manner. Thus Haggo and Kuiper (1983) call for a full lexical entry format à la Jackendoff (1975) which rigorously specifies the set of conditions of use - a codified pragmatics - of each formula. Coulmas $(1979: 244)$ has suggested the use of situational frames for the "conceptual representation of the ensemble of those factors that determine typified speech behaviour" (cf. also Van Dijk $(1977,1981))$. This approach is informally illustrated with a comparison of functionally similar expressions in English and Japanese. Verschueren (1984) thinks that a theory of meaning capable of incorporating a 'prototype-andframes semantics' is what is needed as a starting point for the study of communication whether cross-cultural or not. Each of these proposals may have some worth, but the approach I favour is the one espoused by Wierzbicka (1985b, 1986a, 1986b). She argues that the meanings of linguistic acts can and should be decomposed and represented in a metalanguage of semantic primitives based on natural language but which is culture independent. She demonstrates very convincingly how this reveals the differences and similarities not only between speech acts in a particular language but also across languages and cultures. Besides, this method is not just an ad hoc one for specific parts of language (see Wierzbicka $(1972,1979,1980,1984)$ among others for illustrations).

The analysis in this paper is done in Wierzbicka's framework. The method of analysis essentially involves paraphrasing the linguistic routines in a metalanguage based on intuitively intelligible natural language, and in simple terms which permit a precise comparison of both the similarities and differences between the items in the two languages. The simple terms are intuitive because they are not abstract and are open to verification. They are linked to the ideas that they have in the natural language which can be understood by themselves. Linguistic routines constitute illocutionary acts (cf. Ferguson (1976: 148), Caffi (1984)). As such their meanings (i.e. their illocutionary forces) are amalgams of feelings, assumptions, thoughts, intentions and purposes (cf. Norrick (1978), Searle (1976), Van Dijk (1981), Wierzbicka (1972)). Consequently, the analysis of their meaning, or rather the force and use they have in 
verbal communication to my mind, involves unravelling all the situational, attitudinal, cultural, social and psychological functions, conventions and purposes embodied in them and making these explicit in perusable language. This is what I attempt to do in the following sections. I start with expressions which I have dubbed, for sheer convenience, allo-bono recognitive expressions following Matisoff (1979).

\section{Allo-bono recognitive expressions}

\subsection{English expressions}

Happy events keep happening to people in every society almost dâily. When one realises that something good happens to another, $\mathrm{s} / \mathrm{he}$ has an obligation socially and culturally to give felicitations to that person. This may be done through the enactment of routines. Members of the English speech community, for example, have a repertoire of fixed expressions from which to select in such situations which include inter alia: Congratulations! Well done! Congrats! and in Australian English Good on you! (see Wierzbicka (1986a)). Needless to say, new ones could be created. We focus on the first two of these.

Congratulations can be said to someone who has achieved something personally such as having had a baby, passed an exam or graduated from a course. In such instances something good has happened to the addressee. In addition the addressee is the agent, more or less, of the good event. However, congratulations is also used in situations where the addressee is not a direct agent of the event compared to the situations mentioned before. 'Congratulations on your birthday!' is a frequent and appropriate salutation to people on their birthday in English. Certainly, birthdays are pleasant occasions for the celebrants but one cannot find a direct manipulation of events to lead up to the happy event by the one involved. It could be argucd though that if onc messed up one's life, one would probably not live to attain the anniversary. In a sense, then, one is congratulated on one's birthday presumably for preserving one's life. This is even more evident when the celebration is that of an important age such as twenty-one or fifty. On such occasions, people are usually addressed with the words: 'Congratulations on making it to eighteen/twenty-one/fifty/ seventy-six etc!'.

Similarly, congratulations may be said to someone who has had a stroke of luck, such as having won a lottery. Here too, it is hard to perceive any direct agency of the addressee involved. But it should be remembered that one has to buy a lottery ticket first before one can win. So, if one had not played a game, the happy event would not have occurred. Thus the recipient of congratulations in such cases has done something however indirectly to bring about the pleasant moment. 
Part of the meaning of congratulations should include the fact that it is said to someone to whom something good has happened and who is directly or indirectly the agent of the good thing.

By contrast, well done is said to someone who has done something good such as graduating successfully from a course, winning a race or having produced a good piece of work. It is inappropriate if the good thing is due to a stroke of luck. It is thus infelicitous as a birthday wish. In the same way, it is odd to be used for someone who has won a lottery. Thus well done differs from congratulations in this respect. In fact, the lexical content of well done is very instructive in explaining the difference. It implies that the addressee has done something well. Thus if one has not caused directly, so to speak, the happy event, this expression cannot be used. Furthermore, there is a sense of appreciation and praise for the addressee on the part of the speaker who seems to say that other people cannot do the thing as well as the addressee can do it.

Naturally, anybody to whom something good has happened can be expected to feel pleased. Hence one of the assumptions underlying these expressions is that the addressee feels glad because of the happy event. In this aspect of their meanings both expressions are very similar. It has sometimes been thought that these expressions like any other routines are used perfunctorily; performed without thought or feeling, and are very predictable and as such they are devoid of any feelings and meanings (cp. Owen's (1983) distinction between routine and heartfelt apologies). I don't believe that this is the case. It is the frequency of their occurrence in speech that has led to such perceptions about these routines. As Matisoff (1979: 5) has rightly pointed out, "the formula has become a surrogate for the true feeling, an almost automatic linguistic feature that constant usage has rendered as predictable as the concord in number between subject and object". Thus even if formulae are sometimes said without feelings, their content has feelings and that is what is relevant for the analysis of the conventional illocutionary meanings of the routines.

Next, we consider the illocutionary purpose of these utterances. The point of an illocutionary act - a very important component of its illocutionary force - is different from its real purpose (Austin (1962), Searle (1976)). Furthermore, the social functions of expressive illocutionary acts, under which these routines fall, are also different from both the illocutionary and the real purpose (Norrick (1978), Owen (1983)). What is essential, from a semantic point of view, for an account of these expressions is their illocutionary purpose and maybe their conventionalised social functions. This is because what we are interested in is the expressed intentions of the speaker. Undoubtedly anyone who proffers good wishes to somebody on the occasion of a happy event has the purpose of displaying and expressing to the addressee that $s /$ he feels happy for him/her. Congratulations indicates friendliness, warmth and appreciation for the addressee. Well done, on the other hand, focuses primarily on the good thing that has been done. It registers a speaker's appreciation and admiration for the 
thing that has been done rather than towards the doer of the thing (the addressee). This subtle but important difference between the two expressions is reflected in the components of their meaning that represent their dicta (propositions in Searle's terms). (Compare component (e) of the formula for congratulations and component (d) of that for well done below.)

\section{Congratulations!}

(a) I perceive that something good has happened to you.

(b) I think it wouldn't have happened if you hadn't done something to cause it to happen.

(c) I assume you feel something good because of that.

(d) I want to say the kind of thing that one should say to another when things of this kind happen to him/her.

(e) I say: I feel something good towards you because of that.

(f) I say it because I want to show you what I feel because of it.

Well done!

(a) I know you have done something good that one couldn't expect everyone to be able to do.

(b) I assume you feel something good because of that.

(c) I want to say the kind of thing that one should say to another when $s /$ he does a thing of this kind.

(d) I say: You have done something good.

(e) I feel something good because of that.

It is clear from the analysis that congratulations differs in dictum as well as in terms of whether the addressee is directly or indirectly responsible for bringing about the happy event from well done. Both are, however, similar in the purpose as well as in the feelings involved. These arc very easily discernible from the explications proposed for the two expressions.

\subsection{Ewe expressions}

We proceed to consider some of the fixed expressions used in Ewe in similar situations. When some happy event occurs to someone such as his/her having had a baby, any of the following could be said to the one.

(1a) Máwú sế nú!

God strong side

'God is strong.'

Response:

(1b) Yoo, mia-wó-é dó gbe dá!

O.K. 2PL PL FOC send voice up

'O.K. (it is) you all (who) have prayed.'

(2a) Tógbé-wó sế yú!

Grandfather PL strong side

'Ancestors are strong.' 
Response: (1b), or

(2b) Yoo, mia - to - wó hã́!

O.K. 2PL POSS PRO PL also

'O.K. yours too.'

(3) Đú-wò nú-wó sế nú!

Side $2 \mathrm{SG}$ thing PL strong side

'Beings (things) around you are strong.'

Response: (2)b

(4) Máwú wo dó!

God do work

'God has worked.'

Response: (1)b

(5) Tógbé - wó wo dó!

Grandfather PL do work

'Ancestors have worked.'

Response: (1)b or (2)b

(6) yú - wò nú - wó wo dó!

Side 2SG thing PL do work

'Beings (things) around you have worked.'

Response: (2)b

To facilitate our understanding of these expressions, let us digress a little to look first at gratitude expressing constructions used in Ewe that bear some resemblance to the forms above. The relevant ones are:

(7) Mia-wó

2PL PL -é sẽ yú!

$\left.\begin{array}{l}\text { Wò } \\ \text { 2SG }\end{array}\right\}$ FOC strong side

'(It is) You (who) are strong.'

(8) Mia-wó

2PL PL -é wo dó! $\left.\begin{array}{l}\text { Wò } \\ \text { 2SG }\end{array}\right\}$ FOC do work

'(It is) You (who) have worked.'

The predicates of these latter expressions as well as those of the former ones are identical. In contrast to English thank you, for example, which is used both for material and immaterial services rendered (Coulmas (1981b), Verschueren (1981)), these Ewe expressions are used only for tangible things done for you. ${ }^{4}$

${ }^{4}$ Coulmas (1981b: 74) suggests that acts of thanking can differ from one another along at least four particularly important dimensions. One of these has to do with whether thanks are offered for 
However, the two expressions differ in meaning. Warburton et al. (1968: 129) have erroneously suggested that the difference lies in (7) being more colloquial than (8). Both expressions, to my mind, are used interchangeably, though not synonymously, irrespective of the formality or otherwise of the occasion. It must be conceded though that the preference for one form over the other may have to do with the dialectal background of the spcaker.

Briefly, by using (7) the speaker conveys the idea that the addressee has done something good for him/her. $\mathrm{S} /$ he recognises or admits that the addressee has strength or power presumably over him/her. This is borne out by the literal translation. Furthermore, the speaker feels glad and demonstrates this by uttering the expression. There is an element of praise in (7) which is not found in (8). The speaker, as it were, considers him/herself as being incapable of doing the thing that has been done for him/her. This is evident from the jocular, or rather the 'praise shift response' (as ethnomethodologists would put it) that friends use for (7) but not for (8). The following is a typical exchange between friends:

(9) A: Wò- é sẽ́ yú!

2SG FOC strong side

'(It is) You (who) are strong $=$ Thanks.'

B: Nye-é sế wú wò à?

1SG FOC strong surpass you $Q$

'Am I stronger than you?'

On the other hand, all that is involved in (8) is that the speaker expresses an awareness that the addressee has done something good for him/her and shows that $\mathrm{s} /$ he feels pleased because of it. Incidentally, if we adopt Leech's (1983: 132) idea of politeness maxims one of which enjoins the speaker to maximise praisc of other (addresscc) and minimise praisc of self (spcaker) - the approbation maxim - then we can say that (7) is more polite than (8). This implies and illustrates that different degrees of politeness are involved in the same language for seemingly synonymous expressions. This is a pointer, it seems to me, that politeness strategies are not enough to make explicit the implicit knowledge of linguistic signs (cp. Staab (1983)).

We return now to the expressions for felicitations. Note that one member of the community does something good for another and $s /$ he is said to have strength or have worked. Similarly, when something good happens to you, which you may or may not be responsible for having brought about, it is God, ancestors or other supernatural beings that are said to have strength or have

material goods (e.g. gifts and services) received or for immaterial goods (e.g. wishes, compliments and congratulations) received. The point here is that the Ewe expressions are not used for the latter. 
worked. This is one significant difference between English and Ewe. It is fascinating that the Ewe expressions include the words: Máwu 'God', Tógbéwó 'ancestors' and $\eta u ́$-wò núwó 'beings' or 'forces', (in fact, they refer to spirits and divinities) in them. It is important to realise that English expressions used in similar situations do not encode the idea of the happy event happening to somebody as coming from God or any supernatural powers, but the emphasis is a relationship of speaker and addressee and a concentration on and probably praise of the individual. This should not be surprising to anyone familiar with the Anglo-Saxon tradition of individuality and personal autonomy.

For the Ewes on the other hand, anything that happens to you is the work ultimately of God who may work in diverse ways through the ancestors or other spirits and divinities. So first, we get an idea of how the Ewes conceptualise the causation of good (and bad) things from these expressions. Second, the expressions viewed in their totality furnish excellent glimpses about the structure of the religion of the Ewes. Needless to say, these views are not unique to the Ewes. They are aspects of the African world-view (see Ameka (1985)).

To capture fully the meanings of the expressions, then, we need to enter the belief system of the Ewes and grasp the assumptions that relate to the concepts of God, ancestors, divinities and spirits. The Ewes, like many other Africans, believe in a Supreme Being called Máwú 'God' (Dzobo (1975), Pazzi (1976)). All life and activity, material and non-material, derive from him. Besides God, however, there are other forces or powers which aid not only God in the discharge of his duties, but also humans. These forces comprise spirits - good as well as evil, divinities or lesser deities and ancestors. These various entities in the structure of religion of the Ewes (and of Africans in general) permeate and manifest themselves in all human experiences so that "at every point in the universe of African reality, the person is in contact with life forces that are expressed by means of God, spirits, ancestors, natural objects, even the universe itself" (Williams (1985: 435)). It is not surprising then that God, spirits, divinities and ancestors are ascribed the source of good things that happen to humans and are, as it were, praised for it.

But what exactly is the role of these beings in the life of humans? "The divinities", to use the words of Idowu (1973: 170-171), "are ministers each with his own definite portfolio in the Deity's monarchical government. Each in his own sphere an administrative head of a department. They are also intermediaries between Deity and man especially with respect to their particular functions." These 'ministers', obviously, should play a part in bringing about good things to people. This is why the Ewes can say that they are strong or have worked in bringing about good things that happen to them.

In addition, "[T]he ancestor is a departed spirit who stands in peculiarly close relation to the tribe or the family: the life of the latter has been derived 
from him and because he is still in a sense one with it; his favour or disfavour has therefore a sharply focussed relation to it and is more urgently to be sought or avoided" (Farmer quoted in Idowu (1973: 179)). The ancestors are considered as moral superintendents of the living. As such they do help to cause good things to happen to the living as the routines indicate. All these issues are crucial cultural ideas that must be incorporated in an adequate formulation of the meanings of these expressions.

In Ewe then, because of these views, the praise for good things happening to somebody goes to supernatural beings and not to the individual. This contention is important because it exposes the Anglo-centric nature of Leech's comment that ".. the Approbation Maxim [i.e. (a) Minimise dispraise of other (b) Maximise praise of other, FA] is exemplified in the intrinsic courtesy of congratulations" (Leech (1983: 132)).

Another dimension of the differences between English behaviour and Ewe behaviour as manifested in these routines has to do with how the people think of the happy event. For the English, the happy event happens to an individual and it is the individual's day, while for the Ewes the event is shared by the whole community. Recall that the response to the English expressions is thank you or one of its variants whose meaning can be tentatively paraphrased as:

I perceive that you have done something good for me.

I say: I feel something good towards you because of that.

I say it because I want to show how I feel and to cause you to feel something good.

Notice again that the emphasis is on the speaker and the addressee and their relationship. The focus is on the congratulator having done something good for the recipient of congratulations.

In contrast, however, the Ewe responses $(1 b)$ and $(2 b)$ reproduced below as (10) and (11) portray the communality of the happy event:

(10) Yoo, mia - wó - é dó gbe dá! O.K. 2PL PL FOC send voice up

'O.K. (it is) you all (who) have prayed.'

(11) Yor
Yoo, mia - to - wó hấ!
O.K. 2PL POSS PRO PL also
'O.K. yours too (i.e. your ancestors and divinities etc.).'

(10) indicates that the speaker i.e. the experiencer of the happy event conveys the idea that $s /$ he is conscious of the fact that the good thing would not have happened to him/her if the addressee and other members of the community did not wish for it, even if only passively through their solidarity and group membership. 
(11) further conveys the recognition on the part of the speaker that the good thing was not brought about only by his/her ancestors or divinities etc. but also by those of the addressee and indeed other members of the community as well. This, in fact, illustrates again the communal nature of the beings. God, ancestors, divinities, spirits are not 'personal' and 'private' preserves of individuals but they belong to the whole community and work together in their various roles for the community.

This major difference between the English and Ewe expressions, in my view, largely explains the differences in the situational contexts in which they are used. Thus, in addition to the contexts mentioned so far, the Ewe expressions are also said to someone who has come out of hospital or has had an operation or in short, someone who has been in a dangerous situation but did not succumb to it. In such situations, the English expressions are inappropriate. On the other hand, the English expressions are very appropriate at weddings. An etiquette rule, it is claimed, is that congratulations are said to the groom rather than the bride. However, the Ewe expressions are infelicitous when said to either the groom or the bride or both. Why?

My speculation is that in Ewe society, taking a partner is probably not regarded in itself as a spectacular achievement. Rather, marriage is the beginning of a process aimed at attaining something else (e.g. procreation). What one needs for such tasks is good wishes for prosperity and children etc., and not an adulation of an achievement. On the contrary, in Anglo-Saxon society taking a partner is a great personal achievement and one has to be congratulated for attaining it. Anna Wiezbicka (personal communication) has suggested that congratulations and well done are used felicitously in such a context in English presumably because in this society an individual has to search for and find a 'matching' and 'desirable' partner. If you succeed in doing this you must be praised for attaining something spectacular and good.

Be that as it may, our primary concern is to explicate the messages conventionally conveyed by a speaker who utters these expressions. I suggest the following semantic formulae for the Ewe expressions. The reader is invited to compare the paraphrases with one another and with those proposed for congratulations and well done (on p. 305).

Máwú sế yú!

'God is strong!'

(a) I perceive that something good has happened to you.

(b) I assume you feel something good because of that.

(c) I assume we understand that things of this kind don't happen if God does not cause them to happen.

(d) I assume we feel something good towards God because he has caused this thing to happen to you.

(e) I want to say the kind of thing that one should say to another when things of this kind happen to him/her. 
(f) I say: Grod has done something good for you which people couldn't do.

(g) I feel something good because of that.

(h) I say it because I want to show you what I feel because of it.

Tágbéwó sế nú!

'Ancestors are strong!'

(a) I perceive that something good has happened to you.

(b) I assume you feel something good because of that.

(c) I assume we understand that it couldn't have happened if the ancestors did not want it to happen.

(d) I assume we feel something good towards the ancestors because of that.

(e) I want to say the kind of thing that one should say to another when things of this kind happen to him/her.

(f) I say: the ancestors have done something good for you which people couldn't do.

(g) I feel something good because of that.

(h) I say it because I want to show you what I feel because of it.

$\eta u ̛$-wò nú-wó sế $\eta u ́ !$

'Beings around you are strong.'

(a) I perceive that something good has happened to you.

(b) I assume you feel something good because of that.

(c) I assume we understand that it couldn't have happened if the beings that could cause things to happen to people did not want it to happen.

(d) I assume we feel something good towards the beings because of it.

(e) I want to say the kind of thing that one should say to another when things of this kind happen to him/her.

(f) I say: the beings have done something good for you which people couldn't do.

(g) I feel something good because of that.

(h) I say it because I want to show you what I feel because of it.

Máwú wo dó!

'God has worked.'

(a) I perceive that something good has happened to you.

(b) I assume you feel something good because of that.

(c) I assume we understand that it wouldn't have happened if God did not cause it to happen.

(d) I assume we feel something good towards God because of that.

(e) I want to say the kind of thing that one should say to another when things of this kind happen to him/her.

(f) I say: God has done something good for you.

(g) I feel something good because of that.

(h) I say it because I want to show you what I feel because of it.

Tógbéwó wo dí!

'Ancestors have worked.'

(a) I perceive that something good has happened to you.

(b) I assume you feel something good because of it. 
(c) I assume we understand that it wouldn't have happened if the ancestors did not cause it to happen.

(d) I assume we feel something good towards the ancestors because of it.

(e) I want to say the kind of thing that one should say to another when things of this kind happen to him/her.

(f) I say: the ancestors have done something good for you.

(g) I feel something good because of that.

(h) I say it because I want to show you what I feel because of it.

$\eta u$-wò nú-wó wo dj!

'Beings around you have worked.'

(a) I perceive that something good has happened to you.

(b) I assume you feel something good because of it.

(c) I assume we understand that it wouldn't have happened if the beings that could cause things to happen to people did not do something to cause it to happen.

(d) I assume we feel something good towards the beings because of that.

(c) I want to say the kind of thing that onc should say to another when things of this kind happen to him/her.

(f) I say: the beings around you have done something good for you.

(g) I feel something good because of that.

(h) I say it because I want to show you what I feel because of it.

Certain doubts have been raised by a number of people (including an anonymous referee) concerning the analysis of the Ewe expressions presented here. In general, it is claimed that by the nature of formulaic expressions, the surface compositional meaning of the individual items may not have any bearing on their illocutionary meaning because the latter is derived not so much from the morpho-syntactic and lexical content as from the contextual factors at play in their use. Consequently, it is argued, if these expressions arc routines then it can hardly be proved that speakers are aware of the meaning of the individual items of the expression in question when they use the expressions; let alone the conceptions and cultural ideas that I have claimed are associated with them. In other words, it is questioned whether some of the components of the explications proposed are part of the speakers' knowledge, and even if they are, whether they are accessed when the expressions are used. These are interesting objections but their foundations, in my view, are misconceived.

As I see it, formulaic expressions and for that matter idioms, in general, vary in terms of how frozen and opaque they are. Thus "there are formulae which are exactly like certain grammatical structures of the language in being entirely grammatical and having entirely predictable semantic interpretations" (Haggo and Kuiper (1983: 539)). Others are completely frozen and their meaning bears no relation to the meanings of the individual lexical items. A number of expressions lie between these two end-points of what may be called a frozen- 
ness or opacity hierarchy. For those fixed expressions that are less frozen, (parts of) the meanings of (some of) the individual items usually contribute to the total meaning of the expression in question. Other components of the entire meaning come from the situation (and other contextual factors such as speaker attitudes and emotions) in which the formulae are regularly used (which makes them routines). (Cf. the explication of How dare you! by Wierzbicka (1986b: 103) in which dare is used and its justification.)

I think that the Ewe expressions in question are not completely frozen and so the content of the individual lexical items is relevant for the analysis of their illocutionary meaning. In fact, one way of looking at the expressions is to consider them as having open slots $(X)$ in their structure; viz. $X$ sế $\eta \dot{u}$ and $X w o$ $d b$. One of the tasks of a speaker in communication is to select a term from a set of possible items that could fill the slot to match the appropriate situation. Thus if a human does something good for the speaker, $\mathrm{s} / \mathrm{he}$ fills the slot with an item that refers to and identifies the doer of the good thing (see examples (7) and (8)). If something good happens to somebody else and the speaker wants to show how good s/he feels because of it, one of Máwú (God), Tógbéwó (ancestors), and ņúwò núwó (beings around you) is selected. It can hardly be denied that if these choices are open to the speaker and one of the elements of the communicative competence of a speaker is the ability to choose the appropriate item to fill the slot to suit the appropriate occasion, then a speaker requires a fair amount of consciousness of the items in question in order to communicate felicitously.

Some support for this view can be found in the tendency of some 'puritan' Christians not to use expressions (2a), (3), (5) and (6) (see p. $305 \mathrm{f}$.). They don't use them because they regard the use of such expressions as a recognition and 'worship' of other supernatural beings apart from God. (Such people are generally opposed to the mixing of traditional African practices with Christian practices.) For them, good things that happen to people come only from God (Mawi) and not from the other divinities and ancestors. Therefore they would choose Máwu to fill the slot in such circumstances. This matter, I must add, deserves further investigation especially from a sociolinguistic perspective, but we can regard it in the meantime as instructive for the contention that speakers are aware of the role of the 'beings' mentioned in these expressions and therefore of the content of the lexical items.

Recall also the jocular exchange between friends reported in example (9) (p. 307) which points to the speakers' awareness of the meaning of the individual lexical items. The joke is based on the lexical content of the predicate $s \tilde{e}$ yú 'to be strong'.

If these pieces of evidence are anything to go by, then it is probably fair to claim that part of an Ewe speaker's knowledge of these expressions includes the consciousness of the content and role of the individual items. In addition, 
such notions are accessed when the expressions are used. Thus, a faithful representation of the illocutionary meaning of these expressions, I would argue, should incorporate all these notions.

This argument, some would say, sounds plausible for Ewe, but does it imply that parallel expressions in other languages with 'religious' items in them should have these items explicitly mentioned in their illocutionary meaning? For cxamplc, do the uscrs of English expressions such as: Christ! My God! hell! etc. think of these 'beings', when they utter these formulae? Presumably they don't; nevertheless, it can be argued that the items in question do play a role in the explication of the illocutionary meaning of the expressions in question.

The English expressions, unlike the Ewe ones, can be seen as (semi-)blasphemous and interjectional. In general, they are used to give vent to an emotion which is very often a 'bad' or strong feeling. The speaker conveys this vehemently through the expressions. Although some speakers may not believe in the beings mentioned (cf. Thank God, I'm an atheist), speakers are aware, if only vaguely, that some people think of the use of such words as a bad thing a sin, a taboo - and $\mathrm{s} / \mathrm{he}$ uses it precisely because of this to show that $\mathrm{s} / \mathrm{he}$ feels something very 'bad'/strong about something and therefore breaks the taboo to give expression to this feeling. It is interesting and significant that if speakers have a good or rather weak emotion to externalise, the euphemistic words Goodness and Gee are used instead of God or Jesus, for example. (See Hill (1985) for a meticulous analysis of such expressions.) Consider the following example:
$A$ : Look at this disgusting picture!
$B$ : ?? My Goodness!
$B$ : My God! (Hill (1985: 75))

There is no need for speakers to break a laboo to show that they feel something good about something.

Support for the role that the religious items play in the semantics of the expressions can be found in the slightly different contexts used with constructions which are identical except for the 'religious' items they contain. Thus there is a difference between By God! and By Christ!, between God knows and Christ knows, and even Jesus! is used differently from Christ! Similarly, there is a difference between Thank God and Thank Christ. Compare the following examples and their acceptability judgements:

Thank God for the salvos.

*Thank Christ for the salvos.

(See Hill (1985: $83 \mathrm{ff}$.) for further examples and discussions.)

The finer distinctions between the closely related expressions, I suggest, come 
from the content of the 'religious' items. Therefore they have a bearing on the entire illocutionary meaning of the expressions in question.

Be that as it may, it should be abundantly evident from the analysis of the selected allo-bono recognitive expressions in Ewe and English that although they overlap in situations in which they are used, the range of contexts in which they are used is not identical. Some of the contrasts between the expressions have been explained in terms of the values and cultural practices in the different societies. The expressions clearly have different meanings and portray different cultures. The views of the Ewes on religion are certainly encoded in the routines discussed. The formulae, to my mind, therefore are invaluable pieces of evidence that provide further support for theological as well as anthropological accounts and interpretations of the concepts of God or divinities etc. of the Ewes (and for that matter of Africans). Unfortunately, the use of such evidence has eluded scholars of African thought and religion. If ritual practices should be considered in discourses on African religion, as Williams (1985: 437) has suggested, then I would add and advocate that linguistic routines such as the Ewe ones discussed here which indeed are snippets of everyday ritual should be examined, elucidated and incorporated in such expositions. These should further supplement and complement other pieces of linguistic evidence such as theophorous names and proverbs that have hitherto been employed to sustain arguments about African thought.

\section{Allo-malo recognitive expressions}

Having talked about some of the expressions for showing good feelings to others when good things happen to them, we now turn to those used to show how people feel bad when something unpleasant happens to their interlocutors in social intercourse. We examine English sorry and $I^{\prime}(a) m$ sorry and Ewe bàbŭ among the large number of fixed expressions used in both languages. The differences between the Ewe expression and the English ones have an enormous effect on the use by Ewe speakers (and incidentally speakers of many African languages) of the English forms.

To put the problem in perspective, consider the following communication situation in which this writer was recently involved. I watched a cyclist who, in an attempt to avoid being splashed by water from sprinklers, bumped into a tree, fell off his bicycle and got his sun-glasses broken. I walked up to him and said: "Sorry!" Guess what his reaction was! To my shame, he said "Oh I'm alright, you don't have to apologise; it wasn't your fault...". I was not apologising to him but rather expressing how bad I felt because something bad has happened to a fellow human being for which I was not responsible anyway. Unfortunately, I failed pragmatically because I used the wrong formula (cf. Thomas (1983), Tannen (1984)). Indeed in such a context Ewe hàbă would very much have heen de rigeur. 
It is probably worth noting that I'm sorry would equally have been infelicitous here. However, if it were followed by complements which, so to speak, clarify the fact that it is an expression of sympathy, it would have been adequate. Certainly other formulae involving 'sorry' such as I feel sorry for you would also have been appropriate. But I am sure that the most appropriate thing that my adressee would have loved to hear is either of the following: Hope you're not hurt?, Are you alright?, etc. Such utterances, I might add, do not only sound cynical to me and many other Africans but also seem rude, unsympathetic and irritating when said to someone to whom something bad has happened.

Without doubt, my use of 'sorry' in the above situation is due to L1 interference ${ }^{5}$ but it furthermore reflects one of its uses in the variety of English that I use, viz., Ghanaian English, as well as in a number of other African varieties of English, a fact which has been widely noted. Criper (1971: 11) compares 'educated Ghanaian English' (EGE) - her Type 1, and presumably the variety used by this writer - with native (British) English and notes that: "At the level of context, Type 1 speakers will mostly use the same formal items in the same situations as Native English speakers but there are a few exceptions to this. For example, in the situation of someone hurting himself, a witness to this will say 'sorry' whereas a native English speaker would use 'sorry' only when he has been responsible for some damage to another person". Similar views are expressed by Sey (1973: 109) for Ghanaian English and by Kirk-Greene (1971: 141) and Spencer (1971: 29) for West-African varieties of English. Akere (1978: 414-5) puts the point very vividly for Nigerian English; it also applies mutatis mutandis to Ghanaian and other African varieties of English. He writes: "The form 'Sorry' in English is intended as a genuine apology for a mistake or a wrong doing, for causing some inconvenience to somebody, as an expression of regret for an action not intended but whose result adversely affects or inconveniences another person. In Nigerian English, the semantic field of 'Sorry' has become extended. It is used in addition to the above as an expression of sympathy or pity for a person involved in an accident or for minor things such as tripping, knocking one's toe against a stone and so on. In a classroom situation for example, if a lecturer accidentally drops his lecture notes or a piece of chalk his students would say 'Sorry, Sir'".

Typically, this is explained in terms of interference from the first languages of these speakers in which one form is used both for apology and sympathy which English apparently lacks. This explanation, in my view, is inaccurate because it is not true that English does not have a form used both for apology

5 This kind of interference due to the transfer of the 'rules of speaking' associated with one's native language and speech community to what seems to be a corresponding situation in another language or speech community has been referred to as communicative interference by Wolfson (1983: 62) following a suggestion from Hymes. 
and sympathy. It does. I'm sorry is such a form (see Borkin and Reinhart (1978: 60), Norrick (1978: 262), Owen (1983: 66 et seq.)). It seems to me, therefore, that it is not enough to explain the interference in terms of the lack of lexical equivalent. A more revealing explanation should be sought in the values of the societies and cultures in which the forms are used. An elucidation of the ideas embodied in the forms which determine their use should be a good guidc to help explain this intriguing phenomenon.

The excerpts cited earlier provide very useful hints about the use of sorry in native varieties of English. It is felicitous when the speaker is responsible in some way for the bad thing that has happened. Thus it is said after a speaker has stepped on the addressee's toes, or bumped (accidentally) into him/her, for example. A very common use of sorry is that of asking for repeats in conversation. At first glance this may not seem to imply that the speaker has done anything bad to the other but it should be recognised that one of the norms in English conversation and many more cultures is that conversationalists have to be attentive and co-operative (Grice $(1975,1978)$, Leech (1983), Levinson.(1983)). Hence if one interlocutor has not been attentive and did not get what the other said and asks for a repetition, it is a breach of contract which is a bad thing. Besides, by asking someone to say what has been said again is, more or less, an inconvenience to him/her caused by the inattention of the other interlocutor; hence the latter must apologise for it.

Sorry is also used in turning down invitations and offers. Here again, the speaker is unable to do something and so is responsible for causing displeasure - a bad thing - to the host. Sorry, then, involves a recognition of causing some inconvenience to the other and feeling bad for it.

In all the contexts discussed so far where sorry is used, I'm sorry would also be very appropriate. However, there are situations in which I'm sorry can be used while sorry cannot. For instance, I'm sorry is appropriate as a condolence while sorry is not. In general, it can be said that I'm sorry can be used to sympathise with people while sorry cannot. I' $m$ sorry is also commonly heard in telephone conversations where a caller asks to speak to someone who turns out to be unavailable, the receiver sometimes prefaces this information with I'm sorry. Owen (1938: 56) comments that "though the person receiving the call is not responsible for the unavailability of the person requested, apologies are routinely made". I am not sure if these are apologies. The English folklabel 'apology' as I understand it, refers to the expression of guilt and regret for something bad that the speaker has done. To my mind, the speaker in such a situation is only expressing how bad s/he feels that the one asked for by the caller is unavailable. Incidentally, Owen's corpus does not have an occurrence of sorry in such a context. Considering the use of I'm sorry in such circumstances as apologies, in my view, constitutes another brand of classifying utterances, if not the same as the traditional practice in classical speech act theory of which Owen is so critical. 
Apart from the inappropriate use of sorry for sympathy, I'm sorry further differs from it in that it is used, whether as apology or sympathy, for fairly serious matters (Borkin and Reinhart (1978: 65-66), Fraser (1985: 265 et seq.), Owen (1983: 70)).

The illocutionary purpose of sorry and I'm sorry, however, is the same, i.e. the speaker says either of them because $\mathrm{s} / \mathrm{he}$ wants to show how bad s/he feels because of the bad thing that has happened to the addressce.

The Ewe expression bàbă differs from each of these in some ways. It is a felicitous form for apologising for any inconvenience caused the other, however trivial. Thus if you step on someone's toes or you bump into someone or you cause the slightest hurt to someone you are obliged to say bàbă to the one. In addition it is very appropriate when someone has experienced something bad which you witnessed but which you did not cause in any way. For instance, when someone hurts him/herself or accidentally slips on say a banana skin or stumbles, or is bereaved or grieved you might sympathise with him/her with bàbă.

It should be fairly obvious then that bàbă differs from sorry in so far as the latter cannot be used to sympathise with people. Bàbă also differs from I'm sorry since the former can be used where the situation that triggers the sympathy or apology is trivial. In addition, bàbă is sometimes rendered idiomatically into English as 'consolation' (Adzomada (1968)). While this translation does not capture the whole import of the word, it is indicative of an underlying assumption in its use, viz. the speaker assumes that what is said would help assuage the grief of the addressee. The differences and similarities among the expressions sorry, I'm sorry and bàbă are quite discernible from the following explications of their meanings:

Sorry!

(a) I know I have done something bad to you.

(b) I feel something bad because of that.

(c) I assume you feel something bad towards me because of that.

(d) I want to say the kind of thing one should say to another when $\mathrm{s} /$ he does things of this kind to him/her.

(e) I say I have done something bad to you.

(f) I say it because I want to show how I feel and to cause you to feel something good.

(g) I imagine that you would not want to feel something bad towards me because of what I say.

I'm sorry!

(a) I perceive that something bad has happened to you.

(b) I assume you feel something bad because of that.

(c) I don't want bad things of this kind to happen to you.

(d) I want to say the kind of thing that one should say to another when bad things of this kind happen to him/her. 
(e) I say: I feel something bad because of the bad thing that has happened to you.

(f) I say it because I want to show you how I feel because of it.

(g) I imagine I can cause you to feel something less bad because of what I say.

\section{Bàbă!}

(a) I perceive something bad has happened to you.

(b) I assume you feel something bad because of that.

(c) I feel something bad because I think of bad things that happen to you as if they happened to me.

(d) I want to say the kind of thing that one should say to another when things of this kind happen to him/her.

(e) I say: I feel something bad (for you) because of the bad thing that has happened to you.

(I) I say it because I want to show you how I feel because of it.

(g) I imagine that I can cause you to feel something less bad because of what I say.

If we compare the first component of each of the forms, for instance, it emerges that for sorry the speaker is responsible for the bad thing that has happened which is not necessarily the case for the other two. Note also that bàbă has one component - component (c) - which is not part of the meaning of sorry nor of I'm sorry. This component thus sets bàbă apart from the English expressions.

How do we explain the differences? I maintain that an appeal to the social and cultural milieux in which these expressions are used should help in this task. It seems to me that the restriction on the use of I'm sorry for example, in expressing sympathy for only fairly serious matters has to do with the taboo in English society on making overt one's emotions (cf. Wierzbicka (1985a)).

Furthermore, a deeper and more meaningful explanation for the 'mis-use' of sorry in African varieties of English rather than the superficial one of transfer of L1 translation equivalents can be similarly found. I suggest that in Ewe and many other African languages, forms such as bàbă and indeed sorry are used the way they are presumably because of the pervasive "sense of community, that characteristic of African life", which "to many (...) defines Africanness" (Dickson (1977: 4)). The hallmark of this communal living is that the individual is expected to be responsible not only for himself or herself, but also for the other person as well as for the group. Several practices and aspects of African life provide compelling evidence for this contention. A case in point is the length, use and nature of greetings in many African societies (see Goody (1972), Bird and Shopen (1979), and Naden (1980) among others for illustrations). In the context of the binding corporate life, others are 'brothers' or 'sisters' rather than 'compatriots'. I suggest that it is this canon of life which obliges one to show sympathy to people when, for example, they hurt themselves, or when even the most trivial of misfortunes happens to them.

This view of life is in sharp conflict with the cherished Anglo-Saxon cultural 
tradition which emphasises the autonomy of every individual, abhors interference in other people's affairs and above all adores and reveres each person's privacy. This tradition has many linguistic reflexes; not least among them is the lexical item privacy itself which embodies a characteristic cultural assumption: "it is assumed that every individual would want, so to speak, to have a little wall around him, at least part of the time and that this is perfectly natural and very important" (Wierzbicka (1985a: 164)). In my view, it is an intrusion into the protective wall of the individual, an undue interference in an individual's affairs and an invasion of one's privacy to sympathise with people when little bad things happen to them. Evidently, the conflict between the attitudes in the two cultures is responsible for the miscommunication that occurs due to the extended use of sorry. We see again how social and cultural factors constrain and are reflected in the use and interpretation of linguistic routines. In the next section, we discuss a conversational routine which signifies one of the salient cultural attitudes of the Ewes. It is a manifestation of how language, and in this case linguistic routines, encodes the culture of its users.

\section{An Ewe conversational routine}

A very common and presumably civil practice in Anglo-Saxon culture, for example, is the use of the left hand for almost anything. In Ewe society (and some other African subcultures (see Ameka (1985)) as well as some Asian cultures), the use of the left hand is restricted almost exclusively to the performance of ablutions. Because ablutions are thought of traditionally as 'dirty' or 'filthy', the hand that is customarily used for them is also considered 'dirty' and 'unwholesome'. It is forbidden therefore to use the left hand - the 'dirty' hand - in interaction with people. Its use in social intercourse implies an insult. Thus one cannot pass on something to another or wave to the other with the left hand. It is rude to point to somebody or draw someone's attention to you with the left hand. What African student is not shocked during the first few days in a pan-English country, for example, when people put up their left hands in order to get attention!

Sometimes, serious social disasters occur in cross-cultural communication in relation to this value. Consider the experience of a friend who during the first two days of his arrival in Canada went into a supermarket and asked for meat. He was initially very impressed by the broad smiles of the salesgirl who enthusiastically attended to him. This was, however, shortlived. Disaster soon struck! Much to the chagrin of my friend, the girl passed the parcel of meat over to him with the left hand. What an insult!, my friend thought. He refused to take it. The girl, confused and embarrassed, sought the intervention of her Supervisor but my friend stuck to his guns. Nevertheless, he had to learn that different norms exist in different societies. 
Notwithstanding this cherished norm in Ewe society (and many other African ones), it is recognised that at one time or another, one might not be able to use the right hand in every situation that one ought to. The society permits the use of the left hand in such situations but one must excuse one's behaviour, gain indemnity, so to speak, to violate a social norm. One formula used for this in Ewe is:

(12) Mia (ló)!

Left PRT

'The left hand!'

The response from the adressee is:

(13) Así - é!

Hand FOC

'It is a hand!'

Impressionistically, we can say that the speaker notifies the interlocutor that the hand $s / h e$ is using is the left one and the auditor acknowledges that it is a hand. This implies that the addressee, as it were, grants permission for the use of this hand. It further means that both conversationalists have agreed to suspend the implication of insult in the use of the left hand.

The particle $l o$ that is sometimes tagged on to mia (left hand) is an advisory particle. It can be paraphrased roughly as 'I advise you'. This is further evidence that part of the communication that a speaker puts across to his/her interlocutor by uttering this formula pertains to an advice concerning what $\mathrm{s} /$ he is about to do. The routine can thus be roughly paraphrased as:

I advise you that I am using the left hand.

This routine is one of those that parents and indeed adults in general drill children in. In addition, Ewe, for example, has a repertoire of proverbs that teach morals about the correct use of the left hand as well as its 'unwholesome' nature. One such proverb is:

(14) Wó - mé - tsó - á mia fiá - á ame - fe

3PL NEG take HAB left show HAB person POSS

du - me mó o

town in way NEG

'The left hand is not used to point the way to one's hometown.'

Dzobo (1973: 37) explains this proverb by saying: "the left hand is traditionally considered as an unclean hand because it is used for cleaning the anus, and so if you use it to point the way to your hometown it means that you do 
not think much of your hometown". It should be clear then that if you point to somebody with the left it does imply that you do not think much of him/her. I would go further than that and say that you regard the person as a nonentity.

What then is the conversational meaning of (12) and (13)? I propose the following illocutionary structures for them:

\section{Mia (ló)!}

'The left hand.'

(a) I know that we should not do things of this kind with the left hand.

(b) I assume you understand that I would not have done things of this kind with the left hand if I could.

(c) I cannot do this thing that I want to do with the right hand.

(d) I want to say the kind of thing that one should say to the other when one cannot do things of this kind with the right hand.

(e) I say: I have to do this thing with the left hand.

(f) I feel something bad because of that.

(g) I say it because I want to cause you not to feel something bad because of it.

(h) I imagine that you would not want to feel something bad towards me because of it.

Así - $\dot{e} !$

'It is a hand.'

(a) I understand that you wouldn't do this thing with the left hand if you could have done it with the right hand.

(b) I say: the left hand is a hand.

(c) I don't feel anything bad because of it.

(d) I don't want you to feel something bad because of it.

(e) I say it because I want you to know what I think about it and to cause you not to fccl something bad bccausc of it.

\section{Theoretical implications}

Before I conclude, I would like to consider briefly the implications the approach adopted in the present study may have for a theory of linguistic routines. Haggo and Kuiper (1983) contend that a theoretical investigation of routines can contribute immensely towards an understanding of linguistic performance. They suggest that such a theoretical work involves the following: "First, we need to know what a native speaker of a language who knows its formulae, routines, and speech acts actually knows. This probably means in turn having a theory of psychological and sociological determinants of performance" (Haggo and Kuiper (1983: 534)). They argue, furthermore, that a native speaker knows among other things and most importantly the set of conditions of use of each formula - a codified pragmatics. They also think that it is "possible to construct more than just an anecdotal account of the pragmatics 
of formulae" (1983: 55). I submit that the method of analysis and the representation of the (illocutionary) meanings of items employed in the present study provides a useful model for the construction of more than mere anecdotal accounts of the codified pragmatics of routines. In addition, the framework is quite a useful analytical tool for linguists who want to account for the knowledge of native speakers.

If we accept IIaggo and Kuiper's suggestions then it is reasonable to say that the analysis done in the present study is a modest attempt to attack the first stage of the theoretical investigation of routines, that is, accounting for what native speakers know about their formulae. At the same time, it could provide a basis for deducing certain things about the sociological and psychological determinants of performance - the other stages in the theory of routines. Thus most of the routines have a component of their meaning which is reproduced in part below:

I want to say the kind of thing that one should say to another when ...

Two relevant social and psychological factors in the theory of routines are represented in this component. First, it specifies the social convention (the shared social perception of the situation that a speaker matches the linguistic item with) which the speakers of a speech community have. Second, it implies that the native speaker has a repertoire of expressions in his mental lexicon which could be accessed wholly and used in such a situation. Needless to say, novel exprcssions could be constructed. Further research within the framework used in this study, it is hoped, could make a worthwhile contribution towards the understanding of linguistic performance.

\section{Conclusion}

What native speakers know about routines has to be accounted for in a linguistically precise and explicit manner which should shed some light on the cultural and social aspects of the life of their users. The foregoing is an analysis of the meanings of situationally similar formulaic expressions in English and Ewe. The analysis has revealed a number of things about the psychological and social reality of the respective speech communities which are encapsulated in these routines. Explanations have been offered for the linguistic material in terms of some of the things known about the cultures associated with each of the languages.

The study provides proof of the claim that linguistic routines are indicators of the cultural ecology of their users. In addition, it unfolds some non-trivial characteristics about the institutions, habits, customs, norms, values and 
attitudes of English and Ewe societies. Some of these insights are discernible from the formulations suggested for their meanings.

It has been recognised for a long time now that linguists have an obligation to contribute to the understanding of the nature of human beings and to crosscultural communication and understanding in our multi-cultural and interdependent world. A serious study of the phenomenon of linguistic routines, to my mind, should help linguists in fulfilling this obligation. This is because routines do not only encode psycho-socio-cultural ideas of human beings, but their inappropriate use also aggravates miscommunication in inter-ethnic situations. But such a study should not be a mere cataloguing of the expressions with descriptive commentaries: it should be a rigorous analysis which spells out the illocutionary significance of these expressions and allows the comparison of the illocutionary structures associated with individual expressions within and across languages such as the one undertaken in this paper. Insights gained from such analysis can also be incorporated in pedagogic materials and thereby minimise, if not eliminate, cross-cultural pragmatic failure.

\section{References}

Adzomada, Jacques K., 1968. Dictionnaire des homonymes Ewe. Accra: Waterville.

Akere, Funso, 1978. Socio-cultural constraints and the emergence of a Standard Nigerian English. Anthropological Linguistics 20: 407-421.

Ameka, Felix, 1985. African linguistic routines and African culture. Paper read at the 8th Annual Conference of the African Studies Association of Australia and the Pacific, Canberra. Canberra: Australian National University.

Austin, John L., 1962. How to do things with words. Oxford \& NY: Oxford University Press.

Bird, Charles and Tim Shopen, 1979. 'Maninka' In: Tim Shopen, ed., Languages and their speakers. Cambridge, MA: Winthrop. pp. 59-112.

Borkin, Ann and Susan M. Reinhart, 1978. Excuse me and I'm sorry. TESOL Quarterly 12: 57-69.

Brend, Ruth, M., 1978. Politeness. International Review of Applied Linguistics 16: 253-256.

Rrown, Penelope and Stephen C. Levinson, 1978. 'Universals in language usage: Politeness phenomena'. In: Goody E.N., ed., 1978. pp. 56-289.

Caffi, Claudia, 1984. Some remarks on illocution and meta-communication. Journal of Pragmatics 8: 449-467.

Capo, Hounkpati, C., 1983. Le Gbe est une langue unique. Africa 53(2): 47-57.

Coulmas, Florian, 1979. On the sociolinguistic relevance of routine formulae. Journal of Pragmatics 3: $239-266$.

Coulmas, Florian, ed., 1981a. Conversational routine. The Hague: Mouton.

Coulmas, Florian, 1981b. "Poison to your soul": Thanks and apologies contrastively viewed'. In: F. Coulmas, ed., 1981a. pp. 69-92.

Criper, L., 1971. A classification of types of English in Ghana. Journal of African Languages 10(3): 6-17.

Dickson, Kwesi A., 1977. Aspects of religion and life in Africa. Accra: Ghana Academy of Arts and Sciences.

Drazdauskiene, Maria-Luidvika, 1981. 'On stereotypes in conversation: Their meaning and significance'. In: F. Coulmas, ed., 1981a. pp. 54-68. 
Dzobo, Noah K., 1973. African proverbs: Guide to conduct. (The Moral Value of Ewe Proverbs.) Vol. 1. Cape Coast: University of Cape Coast Press.

Dzobo, Noah K. 1975. An introduction to the indigenous ethics of the Ewes of West Africa. Oguaa Educator 6(1): 82-97.

Edmondson, Willis J., 1981. 'On saying you're sorry'. In: F. Coulmas, ed., 1981a. pp. 273-288.

Ferguson, Charles A., 1976. The structure and use of politeness formulae. Language in Society 5: 137-151. [Reprinted in F. Coulmas, ed., 1981a. pp. 21-35.]

Fraser, Bruce, 1981. 'On apologising'. In: F. Coulmas, ed., 1981a. pp. 259-271.

Goffman, Erving, 1971. Relations in public: Microstudies of the public order. Harmondsworth: Penguin.

Goody, Esther N., 1972. "“Greeting", "begging” and the presentation of respect'. In: J.S. La Fontaine, ed., Interpretation of ritual. London: Tavistock. pp. 39-72.

Goody, Esther N., ed., 1978. Questions and politeness: Strategies in social interaction. London, New York and Melbourne: Cambridge University Press.

Grice, Paul, 1975. 'Logic and Conversation'. In: Peter Cole and Jerry Morgan, eds., Syntax and semantics, Vol. 3: Speech acts. New York: Academic Press. pp. 41-58.

Grice, Paul, 1978. 'Further notes on Logic and Conversation'. In: Peter Cole, ed., Syntax and semantics, Vol. 9: Pragmatics. New York: Academic Press. pp. 113-127.

Haggo, Douglas and Koenraad Kuiper, 1983. Review of F. Coulmas, ed., 1981a: Conversational routine. Linguistics 21: 531-551.

Hill, Deborah, 1985. The semantics of some interjectional constructions in Australian English. (B.A. Honours sub-thesis.) Canberra: Australian National University.

Hymes, Dell, 1968. 'The ethnography of speaking'. In: Joshua A. Fishman, ed., Readings in the sociology of language. The Hague: Mouton. pp. 99-148.

Idowu, E. Bolaji, 1973. African traditional religion: A definition. London: SCM Press.

Jackendoff, Ray S., 1975. Morphological and semantic regularities in the lexicon. Language 51: 639-671.

Kirk-Greene, A., 1971. 'The influence of West African languages on English'. In: John Spencer, ed., 1971a. pp. 289-304.

Lakoff, Robin, 1973. The logic of politeness, or minding your p's and q's. Proceedings of the Chicago Linguistic Society 9: 292-305.

Laver, John, 1981. 'Linguistic routines and politeness in Greeting and Parting'. In: F. Coulmas, ed., 1981a. pp. 289-304.

Leech, Geoffrey N., 1983. Principles of pragmatics. London: Longman.

Levinson, Stephen C., 1983. Pragmatics. London: Cambridge University Press.

Matisoff, James A., 1979. Blessings, curses, hopes, and fears; psychn-ostensive expressions in Yiddish. Philadelphia, PA: Institute for the Study of Human Issues.

Naden, Tony, 1980. How to greet in Bisa. Journal of Pragmatics 4: 137-145.

Norrick, Neal R. 1978. Expressive illocutionary acts. Journal of Pragmatics 2: 277-291.

Owen, Marion, 1983. Apologies and remedial interchanges: A study of language use in social interaction. Berlin, New York and Amsterdam: Mouton.

Pazzi, Roberto, 1976. L'homme ewe, aja, gen, fon et son univers. Lome: Mission Catholique.

Saville-Troike, Muriel, 1982. The ethnography of communication: An introduction. Oxford: Blackwell.

Searle, John R., 1976. A classification of illocutionary acts. Language in Society 5: 1-23.

Sey, K.A., 1973. Ghanaian English. London: Macmillan.

Spencer, John, ed., 1971a. The English Language in West Africa. London: Longman.

Spencer, John, 1971b. 'West Africa and the English language'. In: John Spencer, ed. 1971a. pp. 135.

Staab, Claire F., 1983. Making implicit knowledge explicit: A review of four theories for analysing language by function. Language Sciences $5: 21-35$.

Tannen, Deborah, 1984. The pragmatics of cross-cultural communication. Applied Linguistics 5(3): 189-195. 
Tannen, Deborah and Piyale C. Öztek. 1981. 'Health to our mouths: Formulaic expressions in Turkish and Greek'. In: F. Coulmas, ed., 1981a. pp. 37-54.

Thomas, Jenny A., 1983. Cross-cultural pragmatic failure. Applied Linguistics 4(2): 91-112.

Van Dijk, Teun A., 1977. Context and cognition: Knowledge frames and speech act comprehension. Journal of Pragmatics 1: 211-232.

Van Dijk, Teun A., 1981. Towards an empirical pragmatics: Some social psychological conditions of speech acts. Philosophica 27: 127-138.

Verschueren, Jef, 1981. 'The semantics of forgotten routines'. In: F. Coulmas, ed., 1981a. pp. 133154.

Verschueren, Jef, 1984. Linguistics and crosscultural communication. (Review article.) Language in Society 13: 489-509.

Warburton, Irene P. et al., 1968. Ewe basic course. Bloomington, IN: Indiana University Linguistics Club.

Wierzbicka, Anna, 1972. Semantic primitives. Frankfurt: Athenäum Verlag.

Wierzbicka, Anna, 1979. Fthno-syntax and the philosophy of grammar. Studies in Language 3: $313-383$.

Wierzbicka, Anna, 1980. Lingua mentalis: The semantics of natural language. Sydney: Academic Press.

Wierzbicka, Anna, 1984. Cups and mugs: Lexicography and conceptual analysis. Australian Journal of Linguistics 4: 205-255.

Wierzbicka, Anna, 1985a. Different cultures, different languages, different speech acts: English vs. Polish. Journal of Pragmatics 9: 145-178,

Wierzbicka, Anna, 1985b. A semantic metalanguage for a cross-cultural comparison of speech acts and speech genres. Language in Society 14: 491-514.

Wierzbicka, Anna, 1986a. Does language reflect culture? Evidence from Australian English. Language in Society 15: 349-374.

Wierzbicka, Anna, 1986b. A semantic metalanguage for the description and comparison of illocutionary meanings. Journal of Pragmatics 10: 67-107.

Williams Robert C., 1985. Ritual, drama, and God in black religion: Theological and anthropological views. Theology Today $41: 431-443$.

Wolfson, Nessa, 1983. 'Rules of speaking'. In: Jack C. Richards and Richard W. Schmidt, eds., Language and communication. London, New York: Longman. pp. 61-87. 